\title{
Being 'out' in the field: Who is responsible for health and safety?
}

\author{
Susan M. Cheyne, Oxford Brookes University
}

Any fieldwork requires planning both with your home institution and when carrying out the work in situ. Many universities and institutions require a risk assessment to be approved before any staff or students depart for the field. However, few, if any, universities and institutions actively include sexual orientation or gender presentation safety advice in their fieldwork planning information.

To ensure equality and best practice for everyone, universities, institutions and NGOs should work to safeguard the health and safety of all people working at field sites or projects that they manage. LGBTQ+ primatologists often carry out their fieldwork in countries where it is illegal to be LGBTQ+ or where anyone who is not cisgender heterosexual is subject to intolerance. LGBTQ+ primatologists can face discrimination, harassment, bullying or even violence due to their sexuality or how they present themselves. Even if none of the above occurs, social attitudes to LGBTQ+ people can create an uncomfortable atmosphere in which LGBTQ+ people feel they need to hide their sexuality from co-workers. This can apply to local as well as foreign researchers.

Primatologists from Europe, North America and Australia can expect to receive support from their home institutions, be legally protected against discrimination and to be able to live openly in a (mostly) tolerant society. I argue that excluding sexual orientation from field work planning or from field site and project policies is an oversight. Universities, institutions and NGOs have a responsibility to ensure staff and students are fully cognisant of the potential risks which LGBTQ+ people may face in some countries. A quick search turned up specific advice for LGBTQ+ travellers who are UK and US citizens (UK - https://www.gov.uk/guidance/lesbiangay-bisexual-and-transgender-foreign-travel-advice and USA https://travel.state.gov/content/travel/en/international-travel/before-you-go/travelers-withspecial-considerations/lgbti.html) but these relate predominantly to those travelling for short periods, rather than people away for long periods to carry out research.

Countries where we work to study and conserve non-human primates do not necessarily offer legal protection for LGBTQ+ people, however, a learned society like IPS cannot realistically 
become involved with national laws. Nor do home institutions and universities have any influence over the laws of the countries where their staff and students conduct fieldwork. Nevertheless, universities, institutions and NGOs can take practical actions to safeguard LGBTQ+ primatologists, both foreign and local. In addition to other health and safety guidelines, these policies should include, but are not limited to:

1. Bullying and Harassment Guidelines i.e. a good practice guide for how all members of the field site or project are expected to behave towards each other;

2. Equal Opportunities Guidelines for recruitment of all members of the field site or project;

3. Confidentiality Guidelines so all members are aware of how their data and personal situations are dealt with;

4. Cultural Awareness Guidelines so all new members to the field site or project are aware of what is and is not locally acceptable behaviour;

5. A clear reporting structure for anyone who feels they have a grievance or issue where they need advice, help or intervention from someone senior in the organisation.

In addition to a clear procedure for reporting incidents, a clear strategy for managing these is essential. Many field sites are managed by students or staff who have limited management and human resources experience, thus compounding the possible issues surrounding inappropriate behaviour. The onus is on the senior managers, researchers, directors of the field site or project to ensure that managers have access to appropriate resources and training. In the UK, guidance already exists in the form of BS 8848, the British Standard for organising and managing visits, fieldwork, expeditions, and adventurous activities outside the UK https://www.gov.uk/guidance/safer-adventure-travel-and-volunteering-overseas but compliance is currently voluntary, organisations may not be aware of these standards, and (of course) it only applies to UK organisations, although the content may be useful for all organisations. Your country may provide similar advice. Ultimately, it is crucial to identify who is responsible for the wellbeing and welfare of organisation members (staff, students, visitors etc.) and to have clear policies in place to safeguard everyone. Only by proactively working to ensure equality for all and by having guidelines and proper training for people can we ensure a safe working environment when carrying out primatological fieldwork. 